\title{
THE INFLUENCE OF LOAM TYPE AND CEMENT CONTENT ON THE COMPRESSIVE STRENGTH OF RAMMED EARTH
}

\author{
P. L. NARLOCH ${ }^{1}$, P. WOYCIECHOWSKI ${ }^{2}$, P. JECDA ${ }^{3}$
}

\begin{abstract}
Currently, a worldwide dynamic rise of interest in using soil as a construction material can be observed. This trend is evident in the rapid rise of the amount of standards that deal with soil techniques. In 2012 the number of standards was larger by one third than five years prior. To create a full standardization of the rammed earth technique it is necessary to take into account the diversity of used soil and stabilizing additives. The proportion of the components, the process of element production and the research methods must also be made uniform. The article describes the results of research on the compressive strength of rammed earth samples that differed from each other with regards to the type of loam used for the mixture and the amount of the stabilizer. The stabilizer used was Portland cement CEM I 42.5R. The research and the analysis of the results were based on foreign publications, the New Zealand standard NZS 4298:1998, the American Standard NMAC14.7.4 and archival Polish Standards from the 1960's that dealt with earth material.
\end{abstract}

Keywords: rammed earth, cement stabilization, mineral composition, earth building material, sustainable building material, loam

\section{INTRODUCTION}

One of the tasks of modern construction is the pursuit of reducing energy consumption and the emission of pollutants during the production of construction materials, the transportation of those materials to the construction site and erection of buildings. Among sustainable construction techniques rammed earth seems to be noteworthy. It is a construction technique, which uses locally available soil which is covered by strata of humus.

\footnotetext{
${ }^{1}$ Warsaw University of Technology, Faculty of Civil Engineering, Al. Armii Ludowej 16, 00-637 Warsaw, Poland, e-mail: p.narloch@il.pw.edu.pl, (corresponding author)

${ }^{2}$ Warsaw University of Technology, Faculty of Civil Engineering, Al. Armii Ludowej 16, 00-637 Warsaw, Poland, e-mail: p.woyciechowski@il.pw.edu.pl

${ }^{3}$ Warsaw University of Technology, Faculty of Civil Engineering, Al. Armii Ludowej 16, 00-637 Warsaw, Poland, e-mail: pawel.m.jeda@gmail.com
} 
Despite the fact that recent years yielded many publications about the rammed earth technique, the authors did not find any publications that explain one of the key problems, which is the influence of the soil type on the strength parameters of prepared elements which were either not-stabilized or stabilized with cement. Admittedly many publications and foreign standards feature the recommended granular composition of the soil mixture but the nomograms and granular composition tables differ significantly when it comes to limit values. At the same time, these publications do not offer comprehensive descriptions of the influence of individual minerals or chemical compounds present in the soil on the mechanical features or durability of the material.

In this article the authors have analysed the compressive strength values of rammed earth samples made from mixtures with similar granular composition which use three different types of loam. These types of loam were a waste product from construction sites and their disposal would mean additional costs for the investors. The analysis performed in the article was done to determine the possibility of using different types of loam as a resource used for the production of new construction material. The second aim of the analysis was to determine if some differences in the chemical and mineral composition of used soil will have a significant impact on the strength properties of the material or if such differences can be omitted during the design process of the rammed earth mixtures.

\section{MATERIALS USED FOR RESEARCH}

\subsection{GRANULAR COMPOSITION}

For the purpose of research three types of loam were acquired from different areas around Warsaw. Each type of loam had a different colour - yellow, light grey and dark grey which represented their different mineral or chemical composition. In later parts of the article the loams will be known as: yellow loam (yellow colour), grey loam (light grey colour) and black loam (dark grey colour).

In order to determine the approximate granular composition of each type of loam, aerometric analyses were performed (Fig. 1). Two types of samples of each loam type were tested in this way the first sample was moist loam in the form of powdered lumps and the second sample was dried out dust with grains up to 2 millimetres in diameter. The second sample was obtained by drying out the loam and then grinding the material in a Los Angeles machine. 


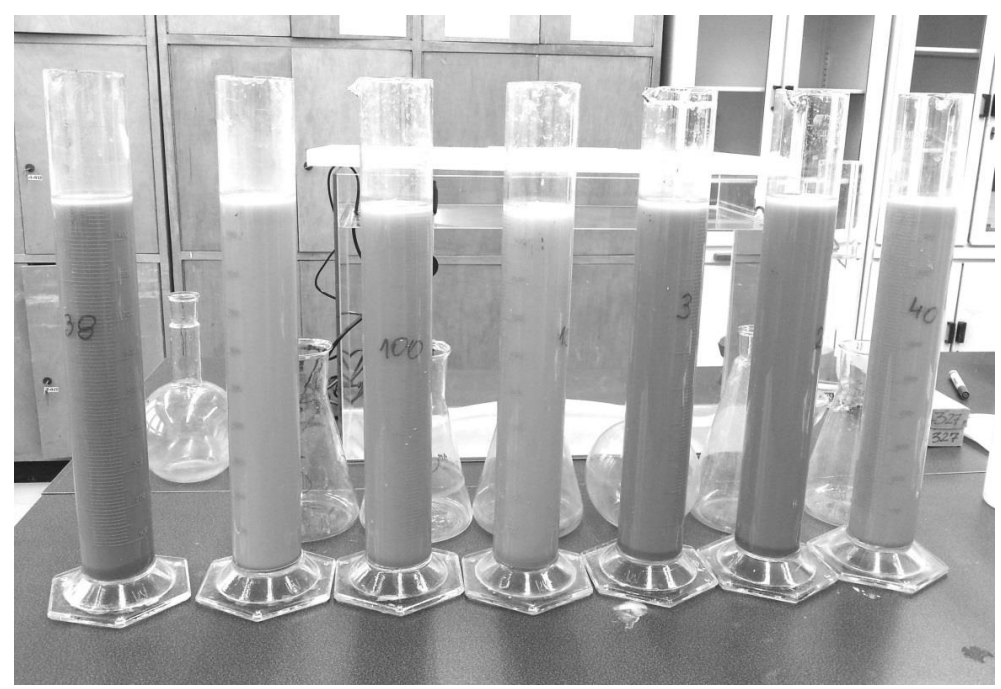

Fig. 1. Aerometric measurements of loams

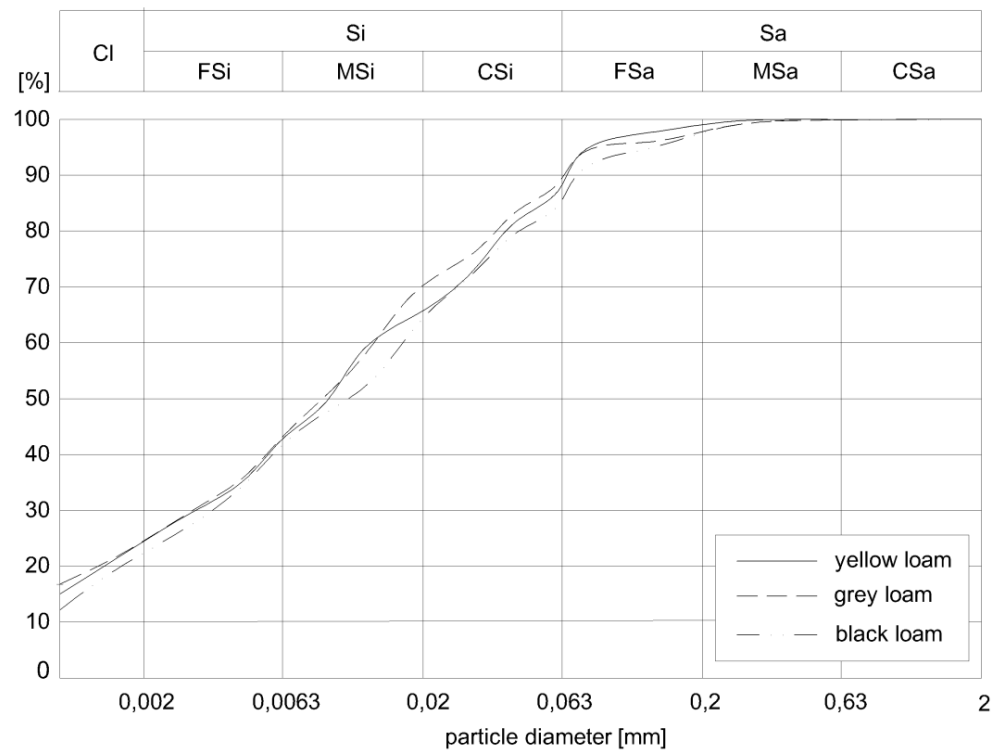

Fig. 2. Graph of granular composition for each type of loam 
The intent of testing the loam in two forms was to determine if the fragmentation process had a significant impact on the granular composition. The test results did not point to any significant differences in the granular composition of the given kind of loam. The tests also did not point to big discrepancies in the granular composition between loams from different locations (Fig. 2). Because of the similarity in granular composition it can be state that any prospective differences in durability testing are due to differences in the chemical or mineral composition of the material.

\subsection{CHEMICAL COMPOSITION OF LOAMS}

The loams used for strength testing also underwent X-ray fluorescence analysis (XRF) to determine their chemical composition. This method is used to identify the particles in a given substance and to determine their quantity. The particles are detected based on the distinctive wavelength (X) or the energy (E) generated by the emission of X-rays. The concentration of a given particle is determined by measuring the line intensity of its characteristics. An example of the obtained spectral graph of the yellow loam sample is shown in Fig. 3 and table 1 shows the identified chemical composition of the tested types of loam.

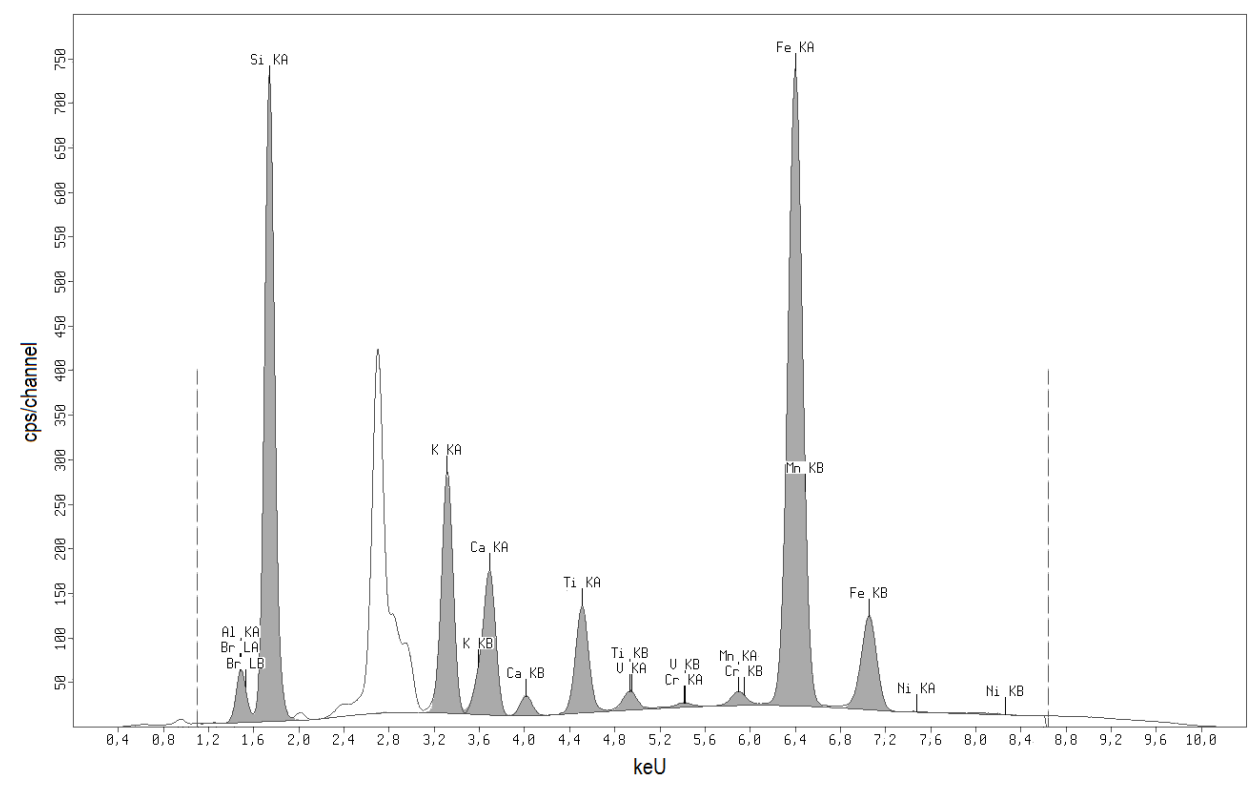

Fig. 3. An example of a spectral graph for a yellow loam sample 
Table 1. The percentage of oxides in the tested loam sample - the XRF testing results.

\begin{tabular}{|l|c|c|c|c|c|c|c|}
\hline & $\mathbf{S i O}_{2}$ & $\mathbf{A l}_{2} \mathbf{O}_{3}$ & $\mathbf{F e}_{2} \mathbf{O}_{3}$ & $\mathbf{K}_{2} \mathbf{O}$ & $\mathbf{C a O}$ & $\mathbf{T i O}_{2}$ & other oxides \\
\hline Yellow loam & 71,64 & 15,60 & 5,30 & 2,10 & 1,30 & 0,77 & 0,24 \\
\hline Grey loam & 68,21 & 15,07 & 5,92 & 2,72 & 4,00 & 0,73 & 0,31 \\
\hline Black loam & 65,41 & 19,10 & 8,97 & 1,42 & 1,32 & 1,02 & 0,29 \\
\hline
\end{tabular}

\subsection{MinERAL COMPOSITION OF LOAMS}

The mineral composition testing of the described loams was done using the thermal analysis method in the Institute of Hydrogeology and Engineering Geology of the University of Warsaw (study done by $\mathrm{Ph}$. D. Ireneusz Gawriuczenkow). The measurements were taken in the Q600 device made by the American company TA Instruments. The conditions applied to the analysis: surplus weight 58-65 $\mathrm{mg}$, sensitivity chosen automatically by the device, heating speed at $10^{\circ} \mathrm{C} /$ minute, air atmosphere. The established mineral composition has been collated in table 2 .

Table 2. The mineral composition of the loam samples.

\begin{tabular}{|c|c|c|c|c|c|c|c|c|c|}
\hline \multirow{3}{*}{$\begin{array}{c}\text { Type } \\
\text { of loam }\end{array}$} & \multicolumn{9}{|c|}{ PERCENTAGE CONTENT OF MINERAL COMPOUNDS } \\
\hline & \multicolumn{4}{|c|}{ Clay minerals } & \multirow{2}{*}{ Goethite } & \multirow{2}{*}{ Siderite } & \multirow{2}{*}{$\begin{array}{c}\text { Calcareous } \\
\text { minerals }\end{array}$} & \multirow{2}{*}{$\begin{array}{c}\text { Organic } \\
\text { substance }\end{array}$} & \multirow{2}{*}{$\begin{array}{c}\text { Quartz } \\
\text { and others }\end{array}$} \\
\hline & Total & Beidellite & Kaolinite & Illite & & & & & \\
\hline Yellow & 27,4 & 24,7 & 2,7 & acc* & 2,0 & - & $1,7 * *$ & - & 69,0 \\
\hline Grey & 39,0 & 2,3 & 1,6 & 35,1 & 2,0 & - & 5,0 & 0,4 & 53,6 \\
\hline Black & 37,8 & 10,4 & 8,5 & 18,9 & 2,0 & - & 6,1 & 0,3 & 53,9 \\
\hline
\end{tabular}

acc* - accessory mineral

$$
\text { ** }-\mathrm{MgCO}_{3}
$$

The granular composition tests have shown that the granular composition of the respective loams is similar, but the mineral and chemical composition tests have shown clear differences in composition on these levels. 


\subsection{RECOMMENDED COMPOSITION OF THE SOIL MIXTURE}

The recommended ratios with regards to granular composition depend on the type and content of stabilizers that are added to the soil mixture. Higher loam content is used when producing nonstabilized rammed earth. Fig. 4 shows the overview of the recommended contents of each fraction in the soil mixture that has no stabilizing additives as established by V. Maniatidis and P. Walker [5]. According to the above authors, the contents of the clay and silt should be around $20-35 \%$ and the contents of the sand and gravel should be at $50-75 \%$ [5].

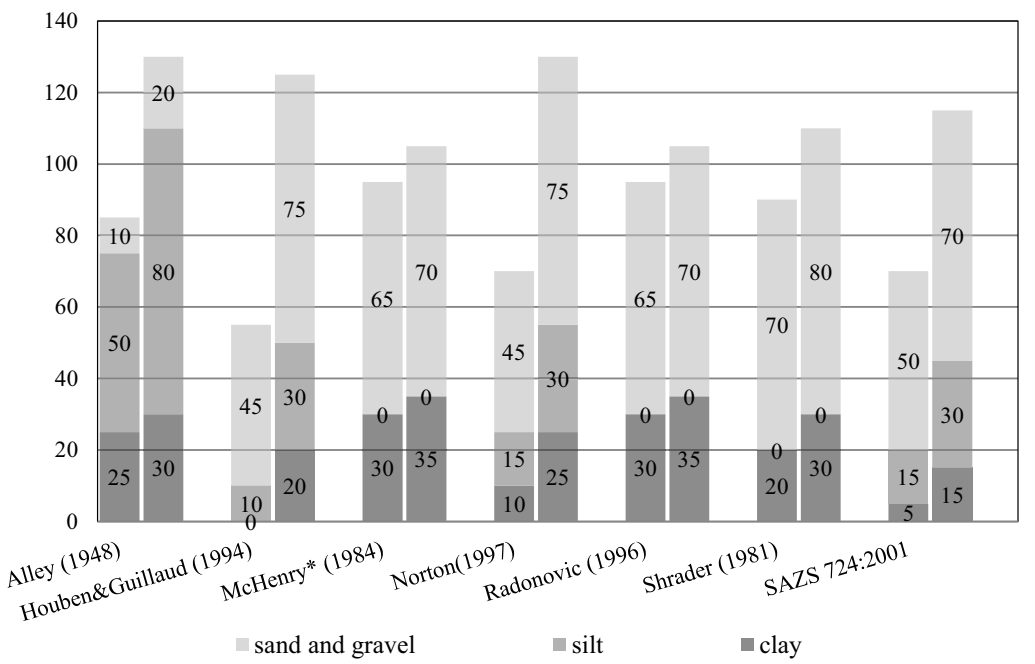

Fig. 4. Mass limit percentage values of each fraction according to [5]

In the case of using stabilizers, the best parameters are achieved by using a higher aggregate content in relation to the cohesive soil. The appropriate choice of the stabilizer depends mainly on the content of smaller fractions and plasticity index of the binder fraction in loam. Charts that show the proportions between the content of the clay and loam compounds in relation to the sand and gravel compound, in the case of soil mixtures that are stabilized with Portland cement, are shown in Fig. 5. This chart is convergent with the upper limit proposed by V. Maniatidis and P. Walker [5] for soil mixtures without stabilizing additives. 


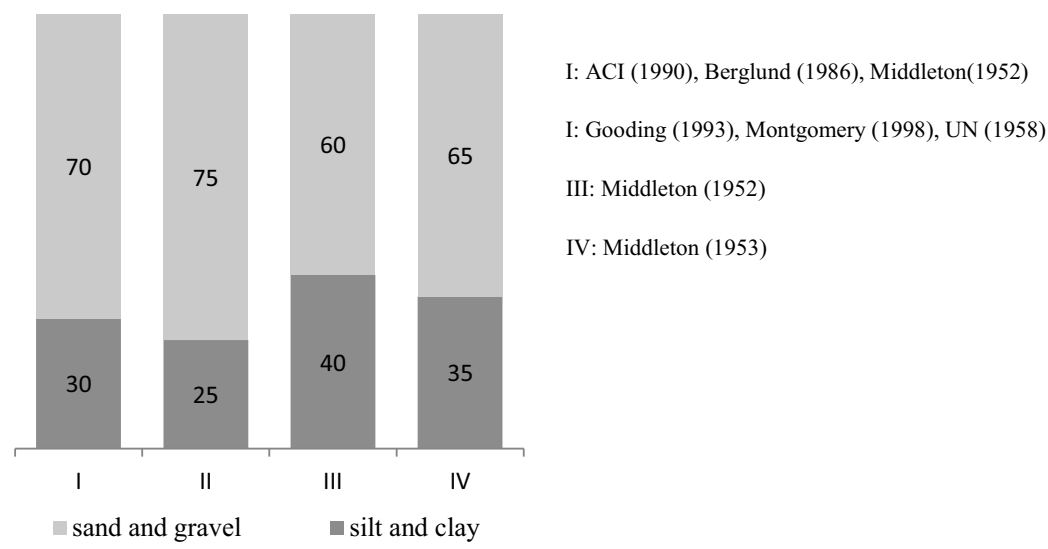

Fig. 5. Recommendations regarding the mixture proportions with added cement [5]

\subsection{CHOOSING THE OPTIMUM COMPOSITION OF THE SOIL MIXTURE}

When choosing the composition of the soil mixture for testing, the results of M. Hall and Y. Djerbib [1] were taken into consideration. These results came from the analysis of compressive strength testing of 10 different non-stabilized soil mixtures. The highest values were achieved by samples with $30 \%$ of silt and clay compounds.

Among those samples, composition 613 which contained $60 \%$ of the sand, $10 \%$ of the gravel and $30 \%$ of the clay and silt compound was optimal. This composition achieved the highest compressive strength and responded best to all of the requirements described above. In the tests performed by the authors of this article sand with a granular composition 0-2 millimetres and gravel 2-4 millimetres were used.

\subsection{GRANULAR COMPOSITION CURVE OF THE MIXTURE}

The granular composition curve of the designed soil mixture is featured in Fig. 6. As it is shown in the Fig. 5 the designed mixture fits, for the most part, in the granular composition area that is recommended by [7]. 


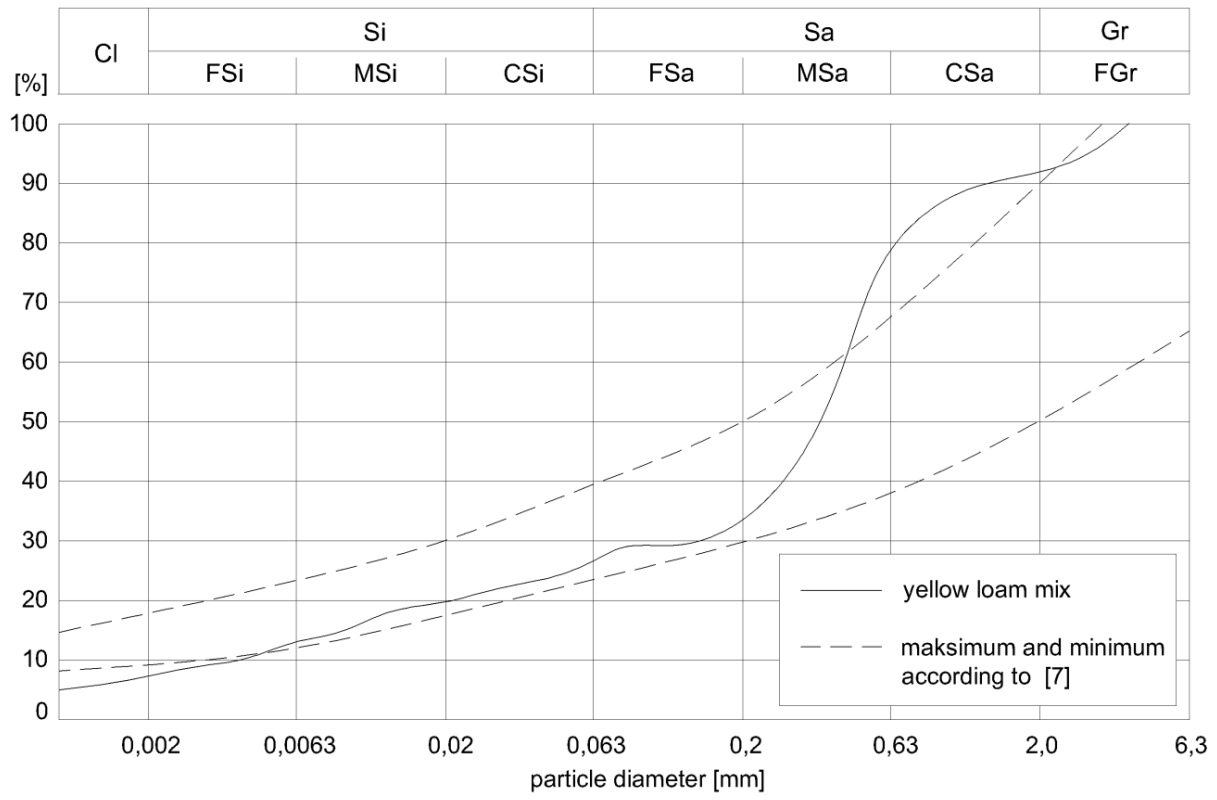

Fig. 6. The granular composition curve of soil mixture 613 used in the research (Maximum and minimum - is a good granular composition area according to [7])

\subsection{STABILIZER}

The role of the stabilizer is to enhance the durability and toughness of the elements made from rammed earth. The most popular of these is Portland cement. This is why in the described research CEM I $42.5 \mathrm{R}$ is used in the amount of $0 \%, 3 \%$ and $6 \%$ relative to the dry matter content of other compounds. 


\section{Preparation of SAMPLe}

\subsection{MOISTURE CONTENT OF SOIL MIXTURES}

In the first place, before moulding the samples, the amount of water needed to create the mixture must be determined. It is necessary not only to get the proper workability of the mixture but primarily to bind the cement and ensure the cohesion of the material. To that end, using the Proctor method, the optimum moisture content must be determined $\mathrm{w}_{\text {opt }}$ It is widely believed that achieving maximum density in this way can lead to reaching the highest element durability.

The results of the measurements of optimum moisture content by using the Proctor method (tamper $2.5 \mathrm{~kg}$, cylinder $1 \mathrm{dm}^{3}$ ) are shown in Fig. 7 and Fig. 8.

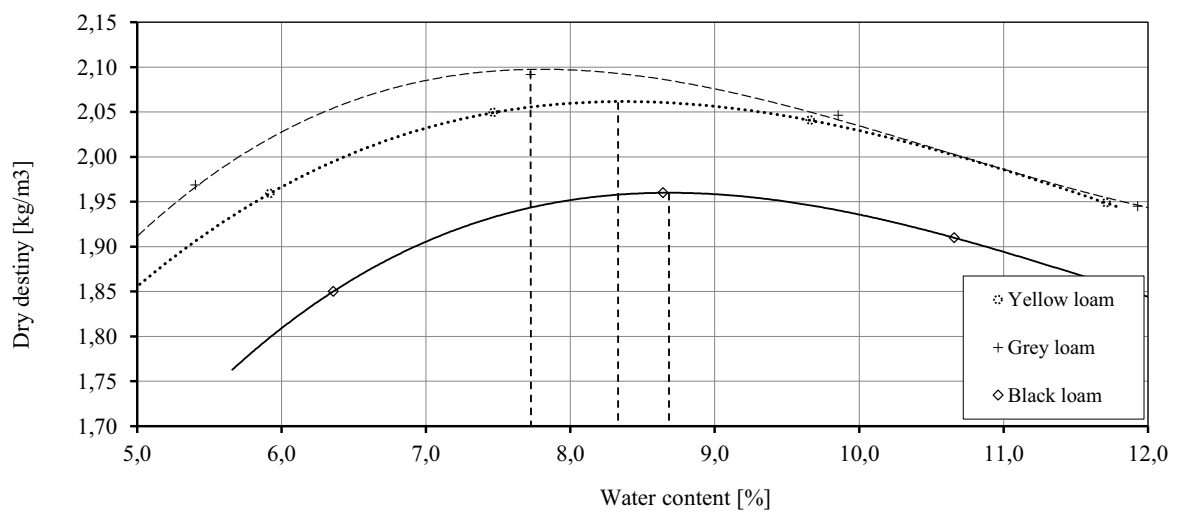

Fig. 7. The Proctor test for soil mixtures without stabilizing additives [2]

When producing mixtures which included cement, the optimum moisture content results gained from the Proctor tests were not used. Considering the noticeable increase in both the looseness and the water demand in mixtures which include cement compared with non-stabilized mixtures, a decision was made to increase the water additive in the mixtures which include cement.

The New Zealand standard NZS 4298:1998, allows for using a soil mixture with moisture content within the range of $-3 \%$ to $+5 \%$ to the optimum moisture content. Taking this into consideration and for the purposes of the research described in this article the authors have designed soil mixtures with the moisture content shown in table 3 . 


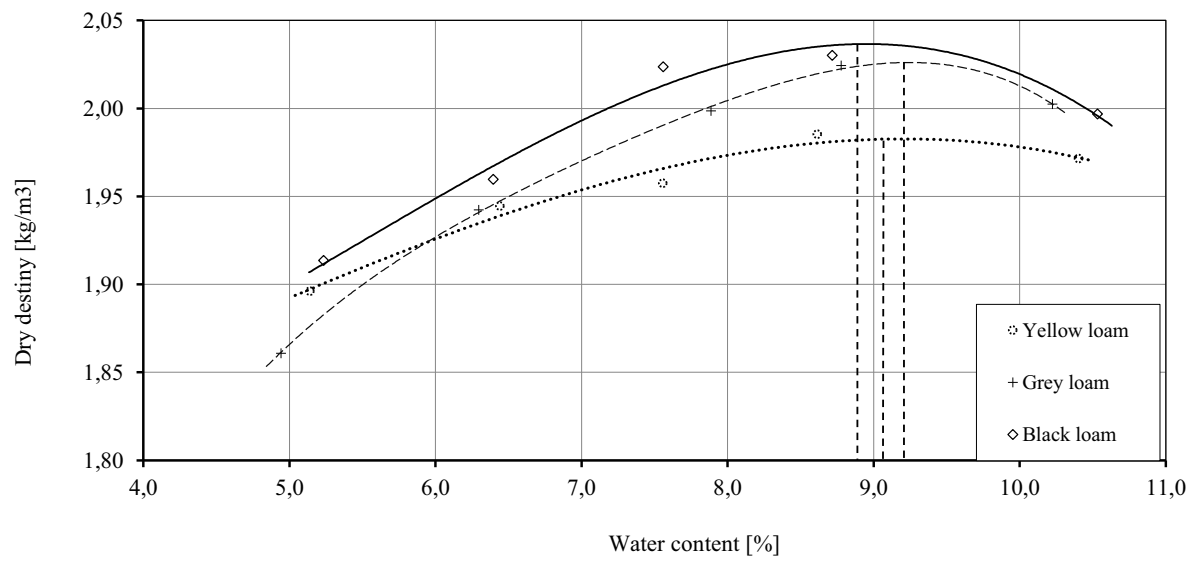

Fig. 8. Proctor test for soil mixtures with a mass additive of $6 \%$ of cement [2].

Table 3. Assumed moisture content of soil mixtures

\begin{tabular}{|c|c|}
\hline Mixture symbol & Moisture content [\%] \\
\hline $6130 \%$ CEM I 42,5R & 8 \\
\hline $6133 \%$ CEM I 42,5R & 10 \\
\hline $6136 \%$ CEM I 42,5R & 12 \\
\hline
\end{tabular}

\subsection{SAMPLE CASTING}

After determining the quantities of all of the components, the first step was to mix the dry material. After getting a homogenous colour of the mixture an appropriate amount of water was added. The mechanical mixer was turned off after two minutes from the moment of adding water. Mixtures prepared in this way were used within 45 minutes, in accordance with the requirements of the New Zealand standard NZS 4298:1998. Preparation of samples was done according to this standard and recommendations described in the publication [1]. Preparation procedure was as follows: a $6.5 \mathrm{~kg}$ tamper is dropped from the height of 30 centimetres twenty times on each of the identical layers of a cubic sample with the side dimension of 100 millimetres. Moulding was done in steel moulds which first had their walls coated with release agent. The prepared elements were directly demoulded and then placed for 28 days in a climate chamber with $95 \%$ relative air humidity and 
temperature of $20^{\circ} \mathrm{C}$, which is significantly higher than the commonly used values that are on the level of $60-75 \%$ humidity. After this period of time no cracks and chips were noticed (Fig. 9). It has to be noted that according to research of C. Beckett and C. Augarde [6] such a high level of moisture has a significant impact on lowering the compressive strength of non-stabilized rammed earth elements.

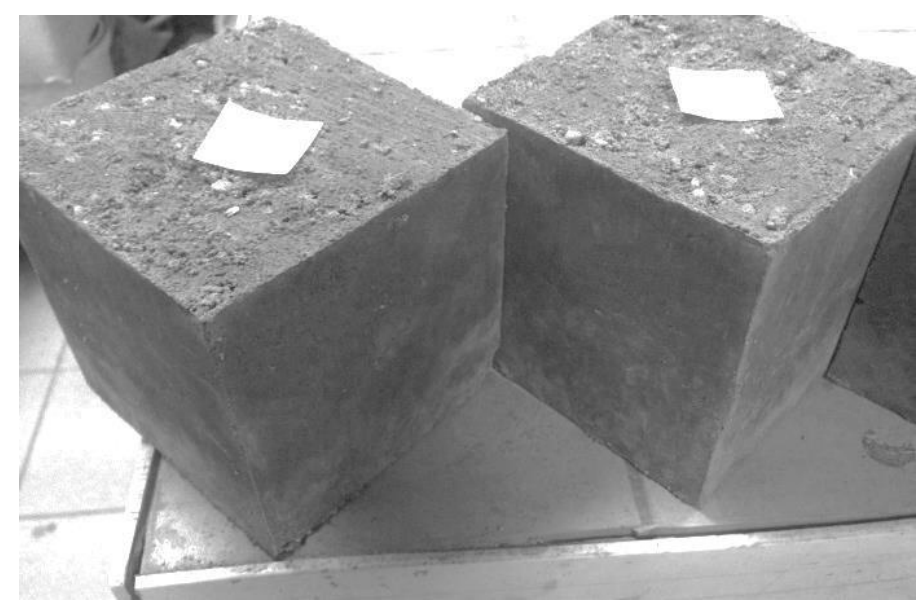

Fig. 9. The appearance of the samples after 28 days of curing

\section{COMPRESSIVE STRENGTH TESTING RESULTS}

After the curing period no cracks were noticed on the surface of the samples, but their upper surfaces were not smooth. Because of this, to ensure an even distribution of load, the upper surface of the samples was evened out with mortar and during the loading of the samples soft fiberboards pads were used. All of the tests were done according to the direction of compacting to ensure the proper destruction model.

The method of testing samples in the compression machine is different than the one used when dealing with concrete samples. Rammed earth, set and condensed in layers, keeps the layered structure both in the monolithic wall and in the moulded samples. We can therefore assume that both, the characteristics of the material and the moulding techniques point to the representative method of determining the loading capacity of the construction by testing strength through loading the sample along the moulding direction. 
To achieve the results of compressive strength testing according to the New Zealand standard, measurements from at least five samples are needed. To increase the representativeness of the results each of the series consists of 10 samples. According to the New Zealand standard NZS 4298:1998 [3], the characteristic compressive strength value is determine by the following formula:

$$
\mathrm{f}^{\prime}=\left(1-1.5 \frac{\mathrm{x}_{\mathrm{s}}}{\mathrm{x}_{\mathrm{a}}}\right) \mathrm{x}_{1}
$$

where:

f' - characteristic strength value;

$\mathrm{X}_{\mathrm{a}}$ - arithmetic mean;

$\mathrm{X}_{\mathrm{s}}$ - standard deviation;

$\mathrm{x}_{1}-$ smallest value among the measurements.

The measurement results have been shown on the graphs (Fig. 10, Fig. 11, Fig. 12), where the rectangle marks the set of results read from the compressive machine, the square mark shows the arithmetic mean from these results (f - average compressive strength according to 14.7.4 NMAC [4]), and the circle marks the characteristic strength value $f^{\prime}$ which takes into consideration the aspect ratio factor $\mathrm{k}_{\mathrm{a}}$ equal to 0,7 according to the New Zealand standard. The correlation between cement content and the compressive strength for different loam types has been shown in Fig. 13.

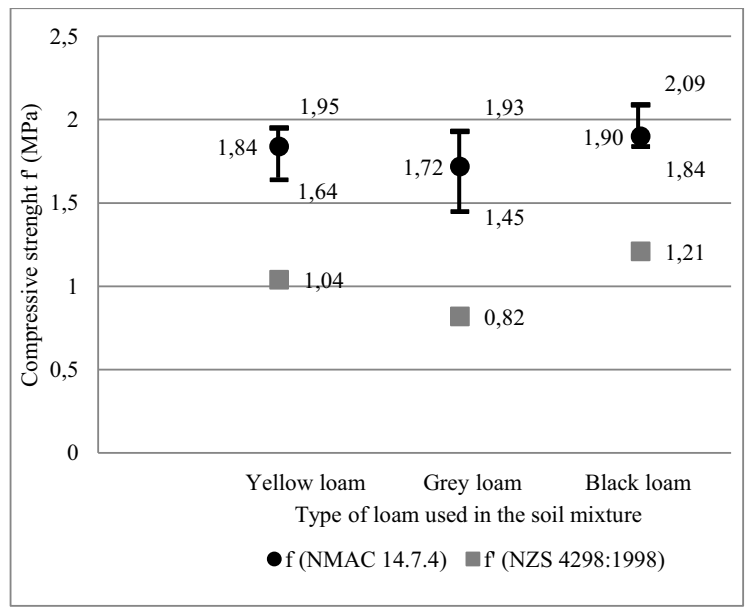

Fig. 10. Compressive strength after 28 days for rammed earth without a stabilizer 


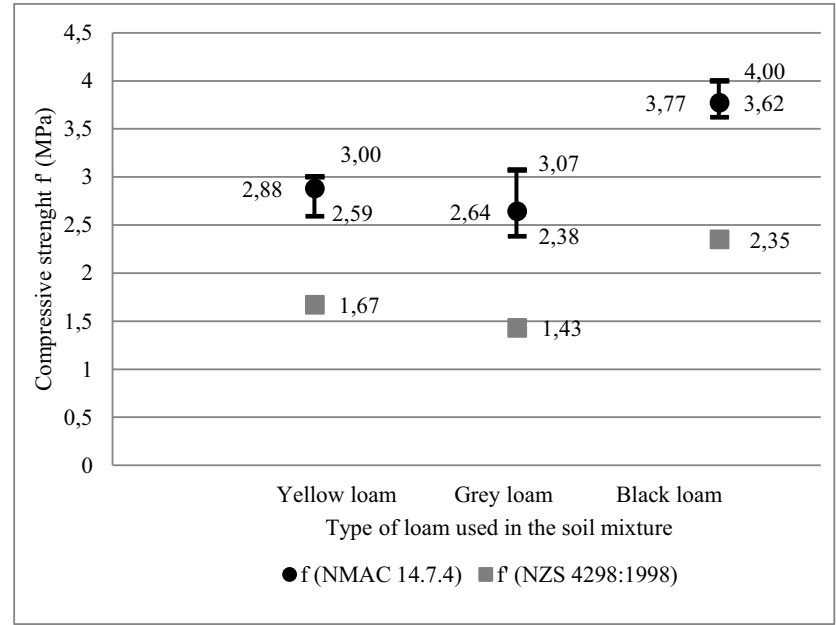

Fig. 11. Compressive strength after 28 days for rammed earth with the addition of $3 \%$ of cement

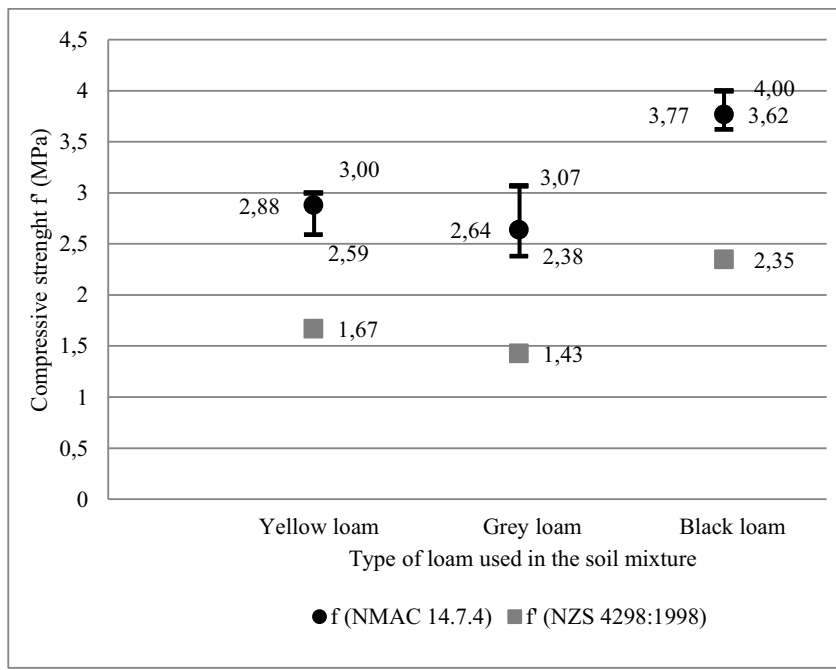

Fig. 12. Compressive strength after 28 days for rammed earth with the addition of $6 \%$ of cement 


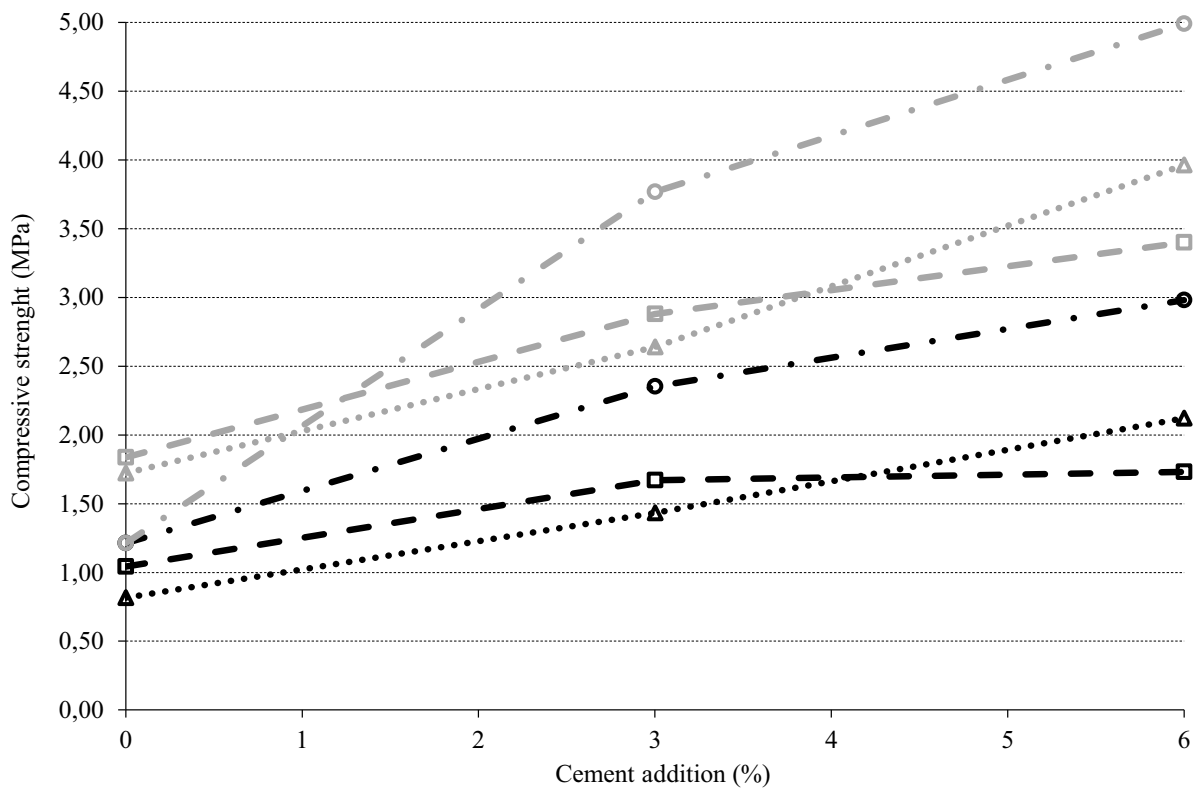

Characteristic compressive strength f' according to NZS 4298:1998:

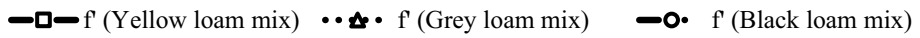

Average compressive strength f according to 14.7.4 NMAC:

$-\square-\mathrm{f}($ Yellow loam mix) $\cdots \triangleq \cdot \mathrm{f}($ Grey loam mix $) \quad-\mathrm{O} \cdot \mathrm{f}$ (Black loam mix)

Fig. 13. Compressive strength depending on the cement content after 28 days

\section{ANALYSIS OF RESULTS AND CONCLUSIONS}

The research performed allows for the forming of the following conclusions:

- When there are no stabilizers involved, the average compressive strength results of all of the tested materials were similar, regardless of the type of loam. However, they did not meet the requirement of minimal characteristic compressive strength equal to $1,3 \mathrm{MPa}$ set by the New Zealand standard NZS 4298:1998;

- In the case of stabilizing the soil mixture with the addition of Portland cement the minimal compressive strength value set in the New Zealand standard was exceeded for every type 
of loam. It seems that using even $3 \%$ of this binder ensures, in each case, that the required strength limit will be met.

- The results acquired in these tests showed a clearly lower level of strength when compared to the results of the work of M. Hall and Y. Djerbib [1], [8]. The authors think that this discrepancy is caused by evident but not recognized (lack of date in [1]) differences in loam characteristics, but also by different curing conditions. In the mentioned work the samples were cured in a chamber with relative humidity $75 \pm 5 \%$ and the samples used by the authors were cured in a chamber with humidity reaching $95 \pm 5 \%$. The rest of the performed actions and assumptions were almost identical in both works. The discrepancy found in the results is probably a result of different curing conditions, which is mentioned in the work of C. Beckett and C. Augarde [6]. This information is in line with the rule that is known in soil construction with regards to the influence of water on the strength of the product.

- Black loam has shown - independent of the cement content - the best results in terms of strength. This may be because of a higher amount of kaolinite in this type of loam (about $8.5 \%$ ) - three to five times more than in other types of loam. Kaolinite as pozzolan has the ability to react with cement hydration products which may in turn lead to higher strength. This notion is justified even more because in the case of soil mixtures without the addition of cement the strength results of all loam types are very similar (from 1.77 to $1.9 \mathrm{MPa}$ ), but with the rise of cement content the differences in the strength values are more noticeable.

\section{ACKNOWLEDGEMENTS}

The authors would like to express their deep appreciation to: the PROCERBUD company for providing access to loams used in the laboratory tests; Patryk Ruszkowski, Maciej Kowański, Martyna Kałużka, Karolina Przybyłek - Students of the Civil Engineering Faculty of the Warsaw University of Technology for their help in laboratory work; Ph.D. Ireneusz Gawriuczenkow and Ph.D. Maciej Maślakowski for working on and sharing the results of the mineral composition analysis of loams used in this research. 


\section{REFERENCES}

1. M. Hall, Y. Djerbib "Rammed earth sample production: context, recommendations and consistency", Construction and Building Materials 18, pp 281-286, 2004

2. P. Jęda "Wpływ rodzaju gliny i zawartości stabilizatora na wytrzymałość na ściskanie ziemi ubijanej”, Bachelor's thesis, Warsaw University of Technology, Poland, 2014

3. New Zealand Standard NZS 4298: 1998 Materials and workmanship for earth buildings - incorporating amendment no. 1.Standards New Zealand, Wellington, New Zealand, 1998.

4. Construction Industries Division of the Regulation and Licensing, New Mexico Earthen Building Materials Code, 14.7.4NMAC Housing and Construction, 2006, Santa Fe, New Mexico

5. V. Maniatidis, P. Walker, "A review of Rammed Earth Construction", Innovation Project "Developing Rammed Earth for UK Housing", Natural Building Technology Group, Department of Architecture \& Civil Engineering, University of Bath, 2003

6. C. T. S. Beckett, C. E. Augarde "The effect of climate on the unconfined compressive strength of rammed earth" Unsaturated Soils: Research and Applications, pp 287-292, 2012

7. H. Houben, H. Guillaud "Earth construction - a comprehensive guide". Second ed. London: Intermediate Technology Publications, 1996.

8. M. Hall, "The mechanisms of moisture ingress and migration in rammed earth walls", PHD thesis, Sheffield Hallam University, UK, 2004 